\title{
Caspase-2 involvement during ionizing radiation- induced oocyte death in the mouse ovary
}

\author{
V Hanoux ${ }^{1,2,3}$, C Pairault ${ }^{1,2,3}$, M Bakalska $^{4}$, R Habert $^{1,2,3}$ and G Livera ${ }^{\star, 1,2,3}$
}

In mammals, the pool of primordial follicles at birth is determinant for female fertility. Exposure to IR during oogonia proliferation and the diplotene stages of ovarian development induced the virtual disappearance of primordial follicles in the postnatal ovary, while half the follicular reserve remained present after irradiation during the zygotene/pachytene stages. This sensitivity difference was correlated with the level of caspase-2 expression evaluated by immunohistochemistry. At the diplotene stage, Western blot and caspase activity analysis revealed that caspase-2 was activated $2 \mathrm{~h}$ after irradiation and a significant increase in the number of oocytes expressing cleaved caspase- 9 and -3 occurred $6 \mathrm{~h}$ after treatment. Inhibition of caspase-2 activity prevented the cleavage of caspase- 9 and partially prevented the loss of oocytes in response to irradiation. Taken together, our results show that caspase-2-dependent activation of the mitochondrial apoptotic pathway is one of the mechanisms involved in the genotoxic stress-induced depletion of the primordial follicle pool.

Cell Death and Differentiation (2007) 14, 671-681. doi:10.1038/sj.cdd.4402052; published online 3 November 2006

Ovarian lifespan is tightly limited by the size of the primordial follicle stock whose formation is initiated during fetal life and is completed at or shortly after birth. ${ }^{1}$ Despite recent data emphasizing a possible follicular renewal in the postnatal mammalian ovary involving the entry into differentiation of germline stem cells, the pool of primordial follicles remains determinant for female fertility. ${ }^{2,3}$ Chemotherapy and radiotherapy have radically increased long-term survival of young cancer patients, but major side effects of these treatments are ovarian failure and infertility. ${ }^{4}$ This premature ovarian failure results from the depletion of follicular reserves, since the nearly complete destruction of primordial follicles occurs in the young adult female mouse ovary 2 weeks after a single exposure to 0.1 Gy of ionizing radiation (IR). ${ }^{5}$ However, the molecular mechanisms involved are still mostly unknown.

Radiation exposure induces cell death via apoptosis, a genetically regulated process that is a physiological way of removing cells that are not needed or are damaged. Irradiation-induced production of DNA double-strand breaks (DSBs) has been shown to play a central role in triggering the mitochondrial apoptotic pathway. ${ }^{6}$ However, other pathways, such as generation of ceramide from cellular membranes, can initiate apoptosis after exposure to ionizing radiation. ${ }^{7}$

Radiation-induced recruitment of the intrinsic apoptotic pathway involves the release of cytochrome $c$ from mitochondria leading to the sequential activation of caspase- 9 and $-3 .{ }^{6}$ Although many upstream components can activate the mitochondrial apoptosis pathway in response to different apoptotic stimuli, ${ }^{8}$ it appears that caspase-2, which belongs to the initiator caspase family, plays a central role in triggering
DNA damage-induced apoptosis through mitochondrial activation. ${ }^{9}$ Two different mRNA species derived from alternative splicing encode two proteins, caspase-2L, which induces cell death, and caspase-2S, a truncated protein which can antagonize cell death. ${ }^{10,11}$ Caspase-2 is required in cytotoxic stress-induced apoptosis before mitochondrial apoptosis ${ }^{12}$ and is activated soon after exposure to various apoptotic stimuli, including ionizing radiation. ${ }^{13}$ Moreover, procaspase2 is the only procaspase present constitutively in the nucleus from which it can induce the mitochondrial apoptotic pathway. ${ }^{14}$ This suggests possible direct DNA DSB-induced caspase-2 activation. However, cytoplasmic cleaved caspase-2 can also signal directly and indirectly to mitochondria. ${ }^{9}$

Mouse fetal ovary arises under the mesonephros at 11.5 days postconception $(\mathrm{dpc})$ as an undifferentiated anlage rapidly colonized by the primordial germ cells (PGCs). These PGCs, also termed oogonia, actively proliferate before initiating the first meiotic prophase from $13.5 \mathrm{dpc}$ onwards. Most oocytes reach the zygotene stage around $14.5 \mathrm{dpc}$ and shortly after enter the pachytene stage. At $18.5 \mathrm{dpc}$ the first diplotene stages are observed in the ovary and all oocytes have reached this stage at birth $(19.5 \mathrm{dpc})$. The oocytes will remain blocked at this stage until their ovulation. Around birth, somatic cells intensely proliferate to enclose the oocyte then forming the primordial follicles. The great majority of these small follicles remain quiescent while a few immediately start growing spontaneously. ${ }^{15}$

Germ cells have long been known to be very sensitive to genotoxic stress. However, this sensitivity greatly changes according to their developmental stage. For instance, meiotic

\footnotetext{
${ }^{1}$ CEA, DSV/DRR/SEGG/LDRG, Laboratory of Differentiation and Radiobiology of the Gonads, Unit of Gametogenesis and Genotoxicity, F-92265 Fontenay aux Roses, France; ${ }^{2}$ Univ Paris 7 - Denis Diderot, U.F.R of Biology, UMR-S 566, F-92265 Fontenay aux Roses, France; ${ }^{3}$ INSERM, U566, F-92265 Fontenay aux Roses, France and ${ }^{4}$ Institute of Experimental Morphology \& Anthropology, Bulgarian Academy of Sciences, Sofia, Bulgaria

${ }^{*}$ Corresponding author: G Livera, Unit of Gametogenesis and Genotoxicity, CEA, Université Paris 7, INSERM U566, CEA/DSV/DRR/SEGG/LDRG, Route du PanoramaBP6, 92265 Fontenay aux Roses Cedex, France. Tel: + 331465499 36; Fax: + 331465499 06; E-mail: gabriel.livera@ cea.fr

Keywords: caspase-2; oocyte; ionizing radiation; genotoxic stress; apoptosis; mitochondrial pathway

Abbreviations: DAB, 3, 3'-diaminobenzidine; dpc, days postconception; dpp, days postpartum; DSBs, double-strand breaks; IR, ionizing radiation; MVH, mouse vasa homolog; PI, propidium iodide; z-VDVAD-fmk, Z-Val-Asp(O-Me)-Val-Ala-Asp(O-Me) fluoromethyl ketone

Received 05.4.06; revised 04.9.06; accepted 18.9.06; Edited by JL Tilly; published online 03.11.06
} 
pachytene oocytes of Caenorhabditis elegans (C. elegans) are hyper-resistant to ionizing radiation compared to diplotene/diakinesis stage oocytes and early embryonic cells. ${ }^{16,17}$ In the current report, we studied the effect of radiation during the course of mouse ovarian development to characterize changes in the radiosensitivity of mammalian ovary. Moreover, we attempted to dissect some molecular mechanisms involved in the genotoxic stress-induced apoptosis of primordial follicles, the stage identified as the most sensitive. In particular, we sought to determine which follicular compartment is most affected by ionizing radiation, and to investigate the role of caspase-2 in the depletion of the follicular reserve after exposure to radiation.

Our data demonstrate a relative radioresistance of oocytes in the course of meiotic homologous recombination repair, while irradiation during oogonia proliferation or just after follicle formation induces virtual destruction of the primordial follicle pool. Moreover, the high radiosensitivity of primordial follicles results essentially in a fast and massive wave of apoptosis of quiescent oocytes involving a caspase-2dependent activation of the mitochondrial pathway.

\section{Results}

IR affects follicle count differently over the course of ovarian development. The effect of ionizing radiation on the developing ovary was analyzed by counting the number of remaining follicles in $8 \mathrm{dpp}$ ovaries after exposure to a total dose of $1.5 \mathrm{~Gy}$ at $12.5,14.5,18.5 \mathrm{dpc}$ and $1 \mathrm{dpp}$.

$\gamma$-Radiation (1.5 Gy) during oogonia proliferation (12.5 dpc) and the diplotene/diakinesis stage of meiosis prophase 1 (1 dpp) greatly reduced the total number of follicles at $8 \mathrm{dpp}$ compared to control (89 and $97 \%$, respectively, $P \leqslant 0.05$, Figure 1a). Exposure to the same dose during the zygotene $(14.5 \mathrm{dpc})$ and pachytene $(18.5 \mathrm{dpc})$ stages only induced respective decreases of 56 and $52 \%(P \leqslant 0.05)$ (Figure 1a).

The primordial follicle pool in the $8 \mathrm{dpp}$ ovary almost disappeared after exposure to $1.5 \mathrm{~Gy}$ on $12.5 \mathrm{dpc}$ and $1 \mathrm{dpp}$ (98 and $99.7 \%$, respectively, $P \leqslant 0.05$ ), whereas 37 and $41 \%$ $(P \leqslant 0.05)$ of primordial follicles remained when irradiation was performed on 14.5 and $18.5 \mathrm{dpc}$, respectively (Figure $1 \mathrm{~b}$ ). Moreover, $1.5 \mathrm{~Gy}$ at $1 \mathrm{dpp}$ greatly reduced the population of primary follicles $(87 \%, P \leqslant 0.05)$, but had no significant effect at $12.5,14.5$ and $18.5 \mathrm{dpc}$ (Figure 1b). Secondary follicles were also affected by ionizing radiation since a significant decrease in their number was observed at all stages when compared to control $(56,37,28$ and $84 \%$ after an exposure to $1.5 \mathrm{~Gy}$ at $12.5,14.5,18.5 \mathrm{dpc}$ and $1 \mathrm{dpp}$, respectively, $P \leqslant 0.05$, Figure $1 b$ ). On the other hand, the number of atretic follicles increased approximately threefold after exposure to $1.5 \mathrm{~Gy}(P \leqslant 0.05)$, except at $1 \mathrm{dpp}$ where no significant effect was observed (Figure 1b).

IR induces apoptosis of the oocyte in primordial follicles. We investigated the deleterious effect of ionizing radiation on $1 \mathrm{dpp}$ ovary since this stage of development is the most sensitive to irradiation, according to our first results. To investigate which follicular compartment (i.e. somatic or germ cells) was the most sensitive to ionizing radiation, we
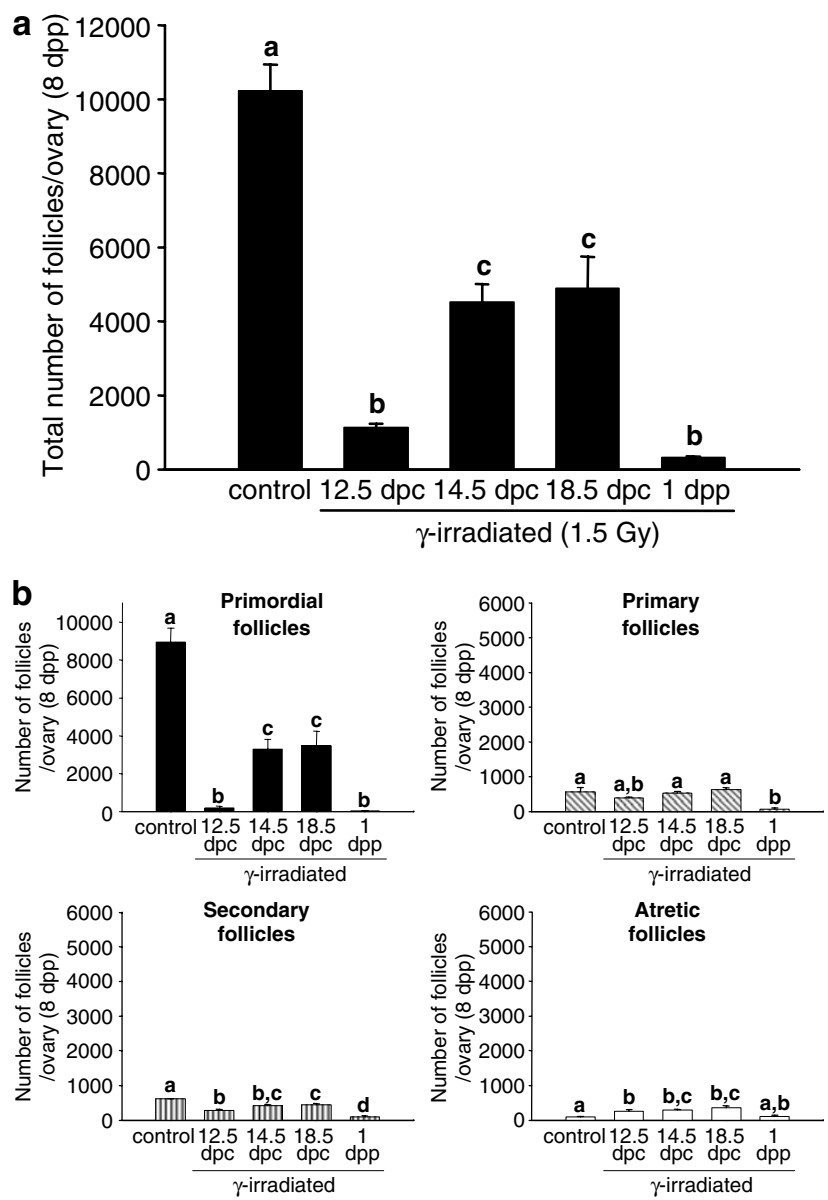

Figure 1 IR (1.5 Gy) affects follicle count differently over the course of ovarian development. Whole-body irradiations were carried out in utero and on neonates. At $8 \mathrm{dpp}$, the ovaries were removed, fixed and prepared for histology. (a) Remaining follicles were counted. (b) Each specific stage of follicular development was identified. Each column represents the mean \pm S.E.M. of at least three independent experiments. Superscripts are different when values are significantly different $P \leqslant 0.05$

first realized dose response experiments to determine which was the lowest dose that eradicated virtually the whole follicle population at $1 \mathrm{dpp}$ (data not shown). This threshold was achieved with a total dose of $0.5 \mathrm{~Gy}$. All further experiments were performed with the 0.5 Gy dose.

Analysis of semi-thin sections of control and irradiated ovaries evidenced compaction of oocyte nuclei from primordial follicles $9 \mathrm{~h}$ postirradiation (Figure 2a). Electron microscopy analysis showed that the normal primordial follicles with two or three flattened granulosa cells possessed round ooplasmic membranes, pale germinal vesicles, and one or more nucleoli (Figure $2 \mathrm{~b}$ ). On the other hand, morphological changes characteristic of apoptosis in the oocytes of primordial follicles, such as progressive chromatin condensation and increase in lipid droplets, were clearly observed postirradiation.

Analysis of $1 \mathrm{dpp}$ ovary after exposure to IR by TUNEL showed that hardly any granulosa cells were TUNEL-positive compared to oocytes (Figure 3a). Nearly all the TUNELpositive cells were also stained for $\mathrm{MVH}$, a specific germ cell 
a

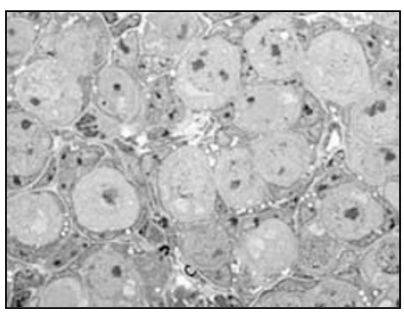

b

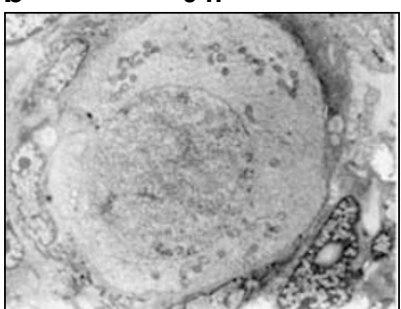

$9 \mathrm{~h}$

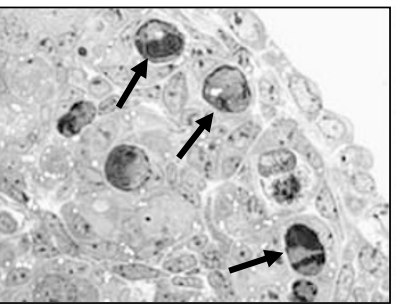

$9 \mathrm{~h}$

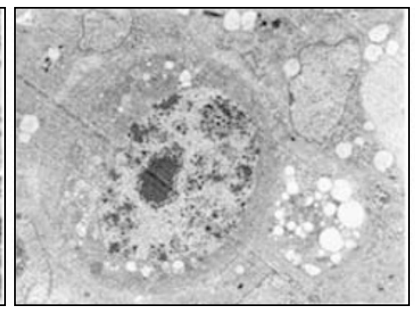

$12 \mathrm{~h}$

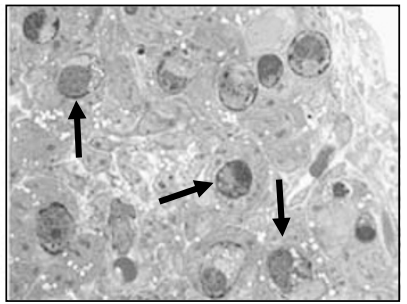

$12 \mathrm{~h}$

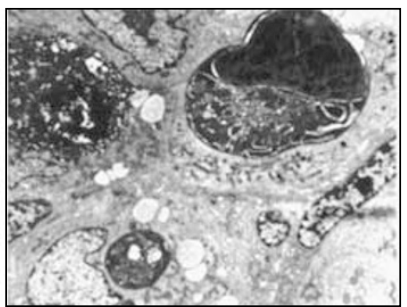

Figure 2 IR (0.5 Gy) induces oocyte apoptosis in primordial follicles. (a) Ultra-thin sections revealed many apoptotic oocytes (arrowhead) 9 and $12 \mathrm{~h}$ post-IR preferentially located in the cortical area of the irradiated ovaries. (b) Representative electron micrographs demonstrating a progressive condensation of the chromatin of the primordial oocyte after exposure to IR

marker. Oocytes from primordial follicles were strongly affected by IR, unlike the oocytes enclosed in growing follicles, which were weakly stained for TUNEL. The percentage of apoptotic oocytes had increased fivefold $(P \leqslant 0.05)$ by $9 \mathrm{~h}$ postirradiation, and peaked at 12 and $24 \mathrm{~h}(5 \pm 0.5 \%$ at $0 \mathrm{~h}$ vs $41.7 \pm 3.4$ and $39.2 \pm 2.6 \%$ at 12 and $24 \mathrm{~h}$, respectively, $P \leqslant 0.05$, Figure $3 \mathrm{~b}$ ). A return equivalent to the basal level was observed $48 \mathrm{~h}$ after irradiation.

IR induces apoptosis in oocytes isolated from $1 \mathrm{dpp}$ ovaries. To confirm the great sensitivity of female germ cells to genotoxic stress, oocytes from 1 dpp ovary, which contains mainly primordial follicles, were isolated using a micromanipulator after enzymatic dissociation and based on their large and round shape (Figure 4a). As shown in Figure 4b, sorted cells expressed the two oocyte markers, MSY2 and c-kit, but not FOXL2, used as marker of granulosa cells, demonstrating the high degree of purity achieved by this isolation technique. Irradiation-induced condensation of the nuclei (a characteristic of apoptosis) of isolated oocytes was investigated using Hoechst staining (Figure 4c). Almost all control sorted oocytes maintained a high nucleocytolasmic ratio with a large and round-shaped nucleus, whereas $98 \%$ of irradiated oocytes displayed condensed and small nuclei $8 \mathrm{~h}$ postirradiation (Figure $4 \mathrm{~d}$ ). At $16 \mathrm{~h}$ after irradiation, all oocytes were dead as shown by PIincorporation, whereas very few control oocytes were PI-positive (Figure 4e).

IR induces the activation of caspase-9 and -3 in primordial follicles. We investigated the expression kinetics of cleaved caspase-3 and cleaved caspase-9 post$0.5 \mathrm{~Gy}$ at $1 \mathrm{dpp}$ to study the involvement of the intrinsic apoptotic pathway in ionizing radiation-induced follicular depletion.
As observed with TUNEL analysis, oocytes from primordial follicles were mainly stained for the cleaved forms of caspase3 and -9 compared to granulosa cells and growing oocytes (Figure $5 \mathrm{a}$ and b). Oocytes expressing cleaved caspase-3 and cleaved caspase- 9 were increased in number from $6 \mathrm{~h}$ postirradiation (four- and threefold, respectively, $P \leqslant 0.05$, Figure $5 \mathrm{a}$ and $\mathrm{b}$ ). More than $60 \%$ of oocytes stained for the cleaved forms of caspase-3 and -9 between 9 and $12 \mathrm{~h}$ after irradiation $(P \leqslant 0.05$, Figure $5 \mathrm{a}$ and $\mathrm{b})$. The proportion of stained oocytes started to decrease significantly at $24 \mathrm{~h}$ $(P \leqslant 0.05)$ and by $48 \mathrm{~h}$ had reached a level equivalent to that observed at $6 \mathrm{~h}$ (Figure $5 \mathrm{a}$ and $\mathrm{b}$ ).

IR changes caspase-2l expression and production in the newborn ovary. RT-PCR analysis of caspase-2 expression was carried out using a primer set for detection of caspase$2 \mathrm{~L}$ and $-2 \mathrm{~S}$. The two forms of caspase-2 mRNAs were detected in the control ovary, but we observed that caspase2L mRNA predominated, and caspase-2S mRNA was barely detectable (Figure 6a). No change was observed in the caspase-2S/-2L ratio after exposure to $\gamma$-radiation (Figure 6a). Quantitative RT-PCR measurement of caspase2 mRNA revealed that caspase-2 expression decreased from $6 \mathrm{~h}$ postirradiation. This was true whether caspase-2 expression was normalized according to $\beta$-actin (i.e. related to the whole ovary) or to MVH (i.e. related only to oocytes) (Figure 6b).

Caspase-2L production in the ovary postirradiation was specifically studied by immunohistochemistry using an antibody that recognizes cleaved as well as procaspase- $2 \mathrm{~L}$. In the $1 \mathrm{dpp}$ ovary $(\mathrm{O} \mathrm{h})$, caspase-2L was detected in the cytoplasm and nucleus of oocytes, and a very weak signal was detected in some somatic cells (Figure $6 \mathrm{c}$ ). IR induced a strong increase in staining intensity, particularly in the oocyte nuclei (Figure 6c). A significant increase in the percentage of oocytes with caspase-2 nuclear staining was observed 
a

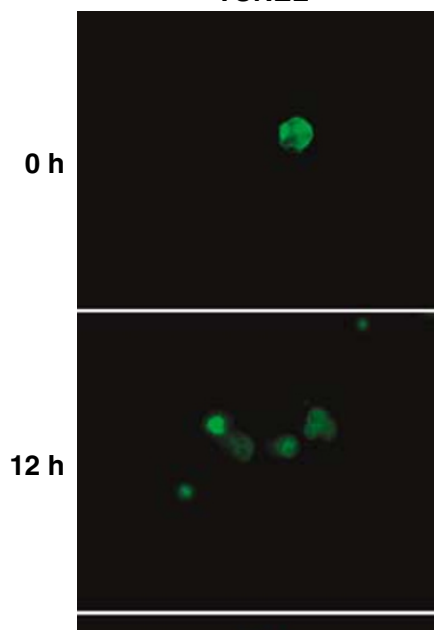

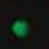

$24 \mathrm{~h}$

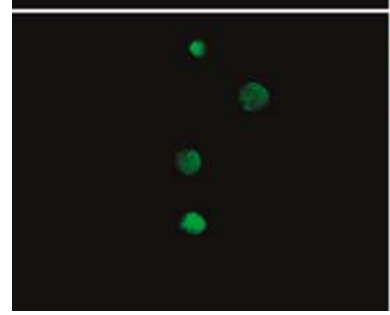

b

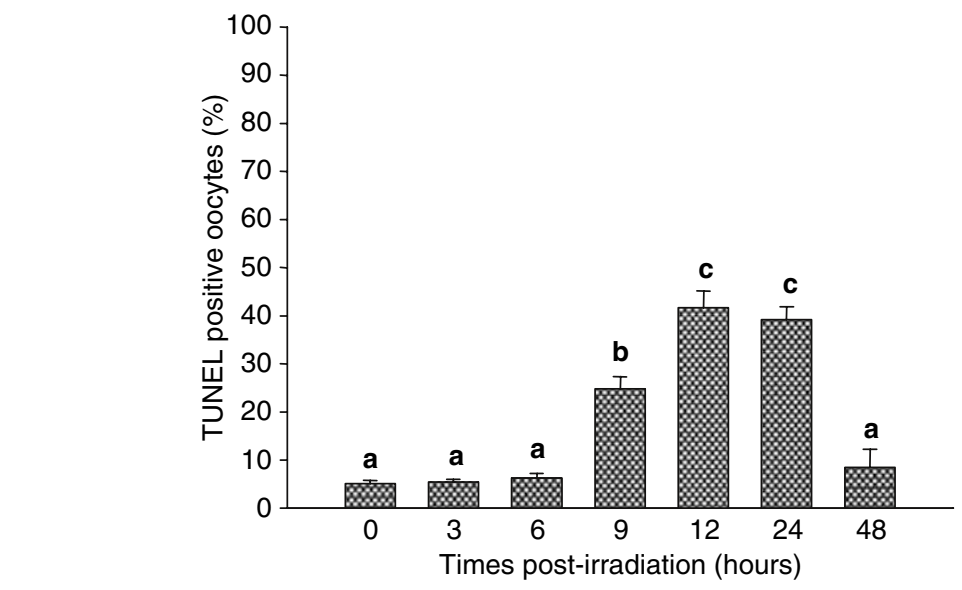

MVH

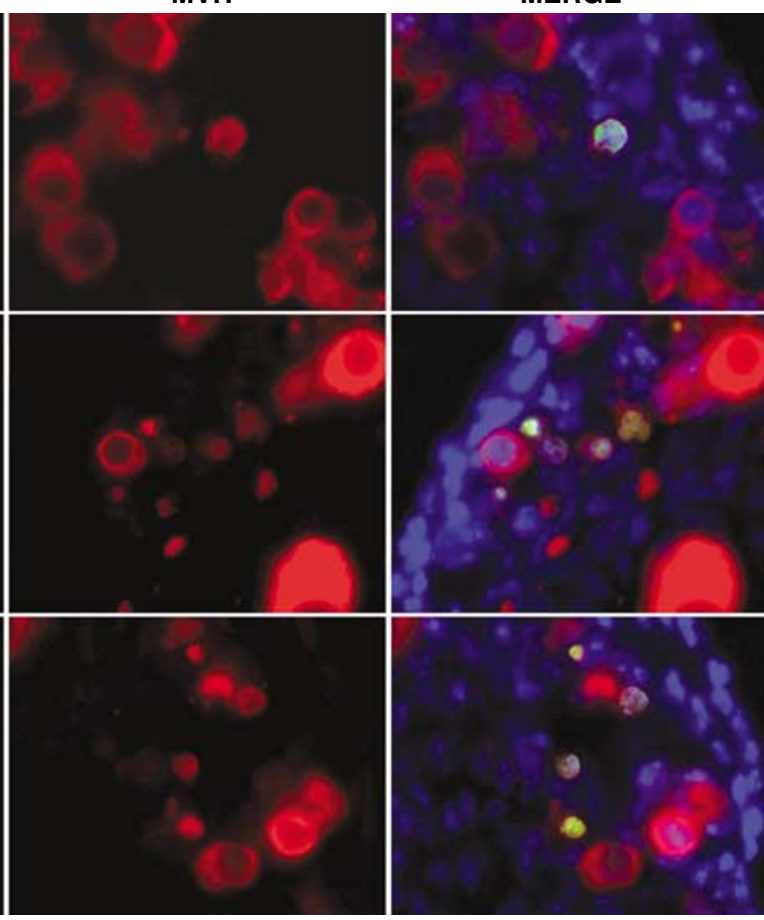

Figure 3 IR $(0.5 \mathrm{~Gy})$ increases the number of TUNEL-stained oocytes. (a) Costaining of ovarian sections for TUNEL and MVH revealed that the majority of TUNELpositive cells were oocytes. (b) The number of TUNEL-positive oocytes increased progressively post-IR. Each column represents the mean \pm S.E.M. of at least three independent experiments. Superscripts are different when values are significantly different $P \leqslant 0.05$

postirradiation $(19 \pm 9.8 \%$ at $0 \mathrm{~h}$ vs $74 \pm 10.2 \%$ and $77 \pm 9.2$ at 3 and $6 \mathrm{~h}$, respectively, $P \leqslant 0.05)$.

Caspase-2L is Activated early in the 1dpp ovary postirradiation. Caspase-2L activation induced by ionizing radiation $(0.5 \mathrm{~Gy})$ in the $1 \mathrm{dpp}$ ovary was studied by measuring the cleavage of the VDVAD-AFC substrate. The specificity of the activity was assessed by using a specific irreversible caspase-2 inhibitor (z-VDVAD-fmk). Specific caspase-2 activity was undetectable in the control ovary and increased from $2 \mathrm{~h}$ postirradiation (Figure 7a). Western blot analysis showed that caspase-2L precursor $(48 \mathrm{kDa})$ was present in the control $1 \mathrm{dpp}$ ovary. Cleavage of the procaspase-2 to the $\mathrm{p} 33$ subunit was observed $2 \mathrm{~h}$ post-IR (Figure $7 \mathrm{~b}$ ). The proform and the processing product were also detected up to $6 \mathrm{~h}$ after irradiation without major change in their content and ratio (data not shown).

Specific caspase-2 inhibitor z-VDVAD-fmk prevents IRInduced caspase-9 activation and increases oocyte survival post-IR. To analyze the involvement of caspase$\mathrm{L} \mathrm{L}$ in the follicular depletion induced by ionizing radiation, ovaries in organ culture were exposed to IR in the presence or absence of z-VDVAD-fmk. As observed in vivo (Figure 5), the number of oocytes expressing cleaved caspase- 9 increased strongly $9 \mathrm{~h}$ postirradiation in organ culture 
a

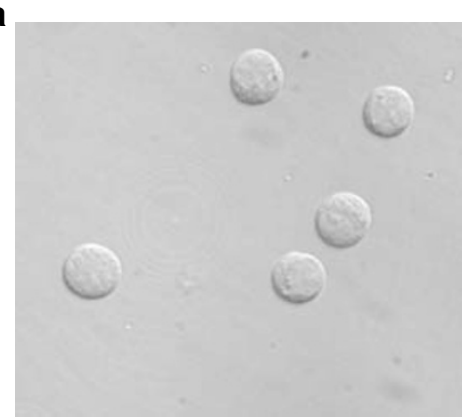

C
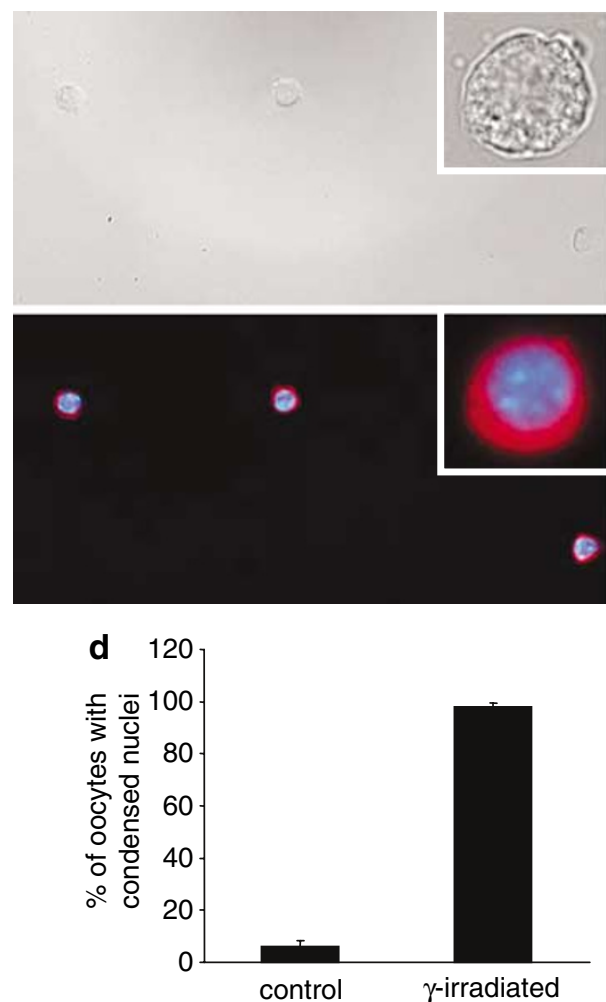

b

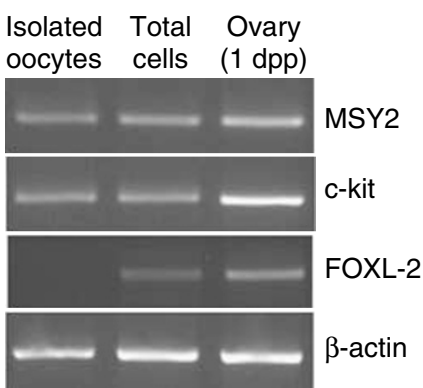

$\gamma$-irradiated

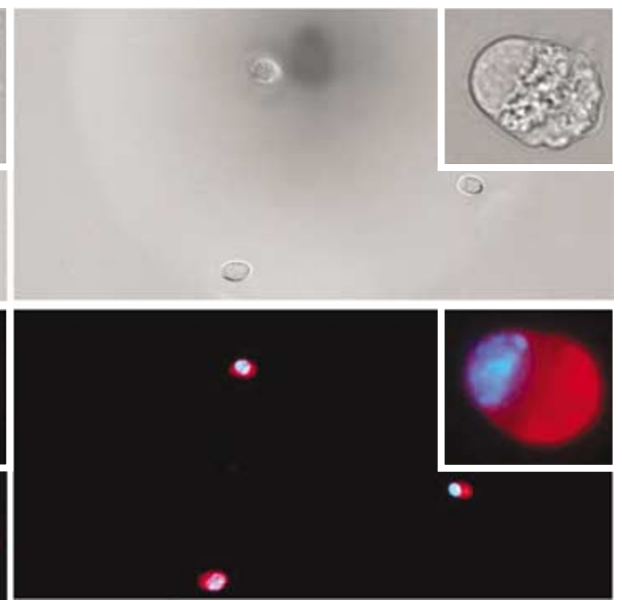

e

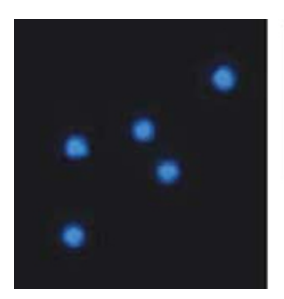

control

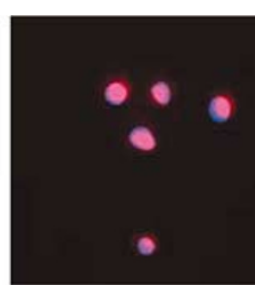

$\gamma$-irradiated

Figure $4 \mathrm{IR}(0.5 \mathrm{~Gy})$ induces apoptosis of isolated oocytes from $1 \mathrm{dpp}$ ovaries. (a) Oocytes were isolated by micromanipulation under an inverted microscope after enzymatic digestion. (b) The purity of the isolated oocytes was assessed using specific markers by RT-PCR. MSY2 and c-kit are two specific markers of oocytes and FOXL-2 is expressed by ovarian somatic cells. (c) Representative micrographs of control and irradiated sorted oocytes stained for MVH and with Hoechst 33342 . The insert demonstrates the chromatin condensation of isolated oocytes $8 \mathrm{~h}$ after exposure to IR. (d) The percentage of oocytes presenting condensed nuclei increased strongly post-IR. Results are the mean \pm S.E.M. representative of three independent experiments. (e) Representative micrographs of PI incorporation demonstrating the death of almost all oocytes $16 \mathrm{~h}$ post-IR

$(78.9 \pm 2.8$ vs $8.6 \pm 1.8 \%$ in control, $P \leqslant 0.05$, Figure $8 a)$. On the other hand, pretreatment with z-VDVAD-fmk $(100 \mu \mathrm{M})$ decreased by approximately $64 \%(P \leqslant 0.05)$ the number of caspase-9 positive oocytes after exposure to IR (Figure 8a). Similar results were obtained when observing cleaved caspase-3 (data not shown). The number of surviving oocytes in the presence of z-VDVAD-fmk $48 \mathrm{~h}$ post-IR had sharply decreased but remained nearly twice that of untreated irradiated ovaries $(577 \pm 69$ vs $307 \pm 75, P \leqslant 0.05$, Figure 8b). DMSO (vehicle) had no significant effect compared to controls (data not shown).
Caspase-2L does not colocalize with $\gamma \mathrm{H} 2 \mathrm{AX}$ foci following exposure to IR. DNA DSBs induced by genotoxic stress are considered to be the most lethal damage to the cell. Analysis of $\gamma \mathrm{H} 2 \mathrm{AX}$ expression (a marker of DSBs) on ovarian sections by immunofluorescence revealed the appearance of many $\gamma \mathrm{H} 2 \mathrm{AX}$ foci in the oocytes nuclei $3 \mathrm{~h}$ postirradiation $(0.5 \mathrm{~Gy})$, whereas almost no $\gamma \mathrm{H} 2 \mathrm{AX}$ foci were detected in somatic cells (Figure 9a). No clear colocalization of caspase-2L and $\gamma \mathrm{H} 2 \mathrm{AX}$ foci was observed in the germinal vesicle $3 \mathrm{~h}$ after exposure to IR (Figure 9b). 
a
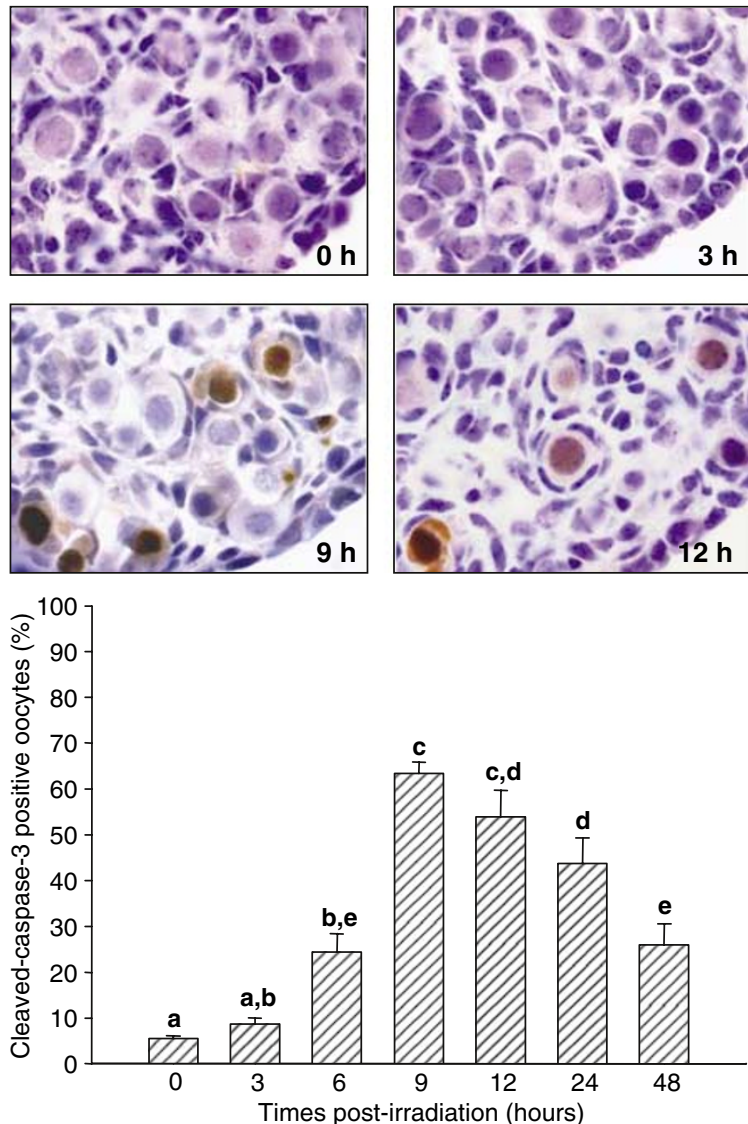

b
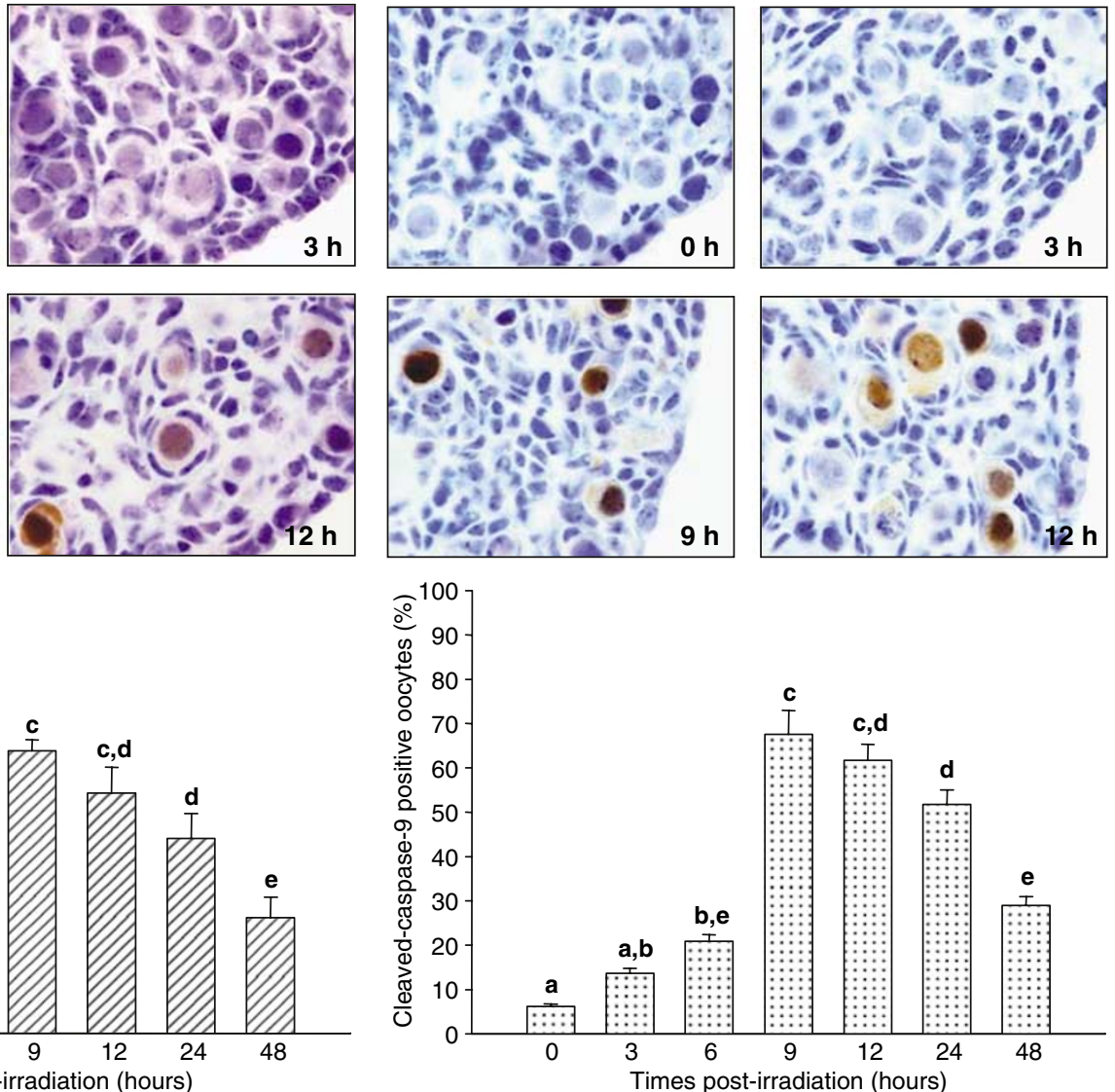

Figure 5 IR (0.5 Gy) induces the activation of caspase-3 (a) and caspase-9 (b) in the oocytes contained in primordial follicles. Immunohistochemistry analysis revealed that the number of oocytes stained for cleaved caspase-3 and -9 increased progressively postirradiation in the 1 dpp ovary. Each column represents the mean \pm S.E.M. of at least three independent experiments. Superscripts are different when values are significantly different $P \leqslant 0.05$

Caspase-2L expression correlates with oocyte radiosensitivity throughout ovarian development. Caspase-2 expression was investigated in the ovary from $12.5 \mathrm{dpc}$ to $2 \mathrm{dpp}$ (Figure 10).Staining of caspase-2 was faint on $18.5 \mathrm{dpc}$, intensified on $0 \mathrm{dpp}$, and was maintained thereafter. Only diplotene stage oocytes from small quiescent follicles displayed a strong signal, while oogonia (12.5 dpc), zygotene (14.5 dpc) and pachytene (17.5) stage and diplotene stage oocytes from growing follicles (2 dpp) bore no detectable staining.

\section{Discussion}

This report demonstrates that the sensitivity of the mammalian ovary to IR changes throughout development, and provides new data on follicular depletion and on apoptotic pathways activated in the oocyte after exposure to genotoxic stress.

Exposure to IR during oogonia proliferation $(12.5 \mathrm{dpc})$ and the diplotene/diakinesis stage of meiosis prophase I (1 dpp) induces an almost total disappearance of the follicular reserve. This confirms previous data obtained in the rat. ${ }^{18,19}$ Interestingly, we show that the deleterious effect of $\gamma$-radiation is less marked when irradiation is performed during the zygotene/pachytene stage (14.5-18.5 dpc) in the mammalian ovary, since approximately half of the primordial follicles remain in the ovary at $8 \mathrm{dpp}$. This low oocyte radiosensitivity at this stage could be due to a low basal ratio of pro- and antiapoptotic regulators, as described in different cell lineages. ${ }^{20}$ Here, we demonstrate that caspase-2 expression is initiated when oocytes reach the diplotene stage. Therefore, the radiosensitivity of mouse oocytes in the course of ovarian development appears to be closely related to the pattern of caspase-2 expression. Another explanation of radioresistance during the zygotene/pachytene stage could be the high level of expression of the DNA repair machinery necessary for meiotic homologous recombination, as already described in C. elegans. ${ }^{16}$ Interestingly, oogonia radiosensitivity does not seem to be related to caspase-2 expression, indicating that IR probably triggers the death of these mitotic cells through a different mechanism.

Our results demonstrate that IR depletes the follicular reserve in mouse newborn ovary. Our three-pronged approach (i.e. electron microscopy, TUNEL and oocyte isolation) shows that this destruction of the primordial follicle pool results specifically from a rapid and massive wave of apoptosis of the germinal compartment. Growing oocytes were little affected compared to quiescent oocytes, in 


\section{a Times post-irradiation (Hours)}
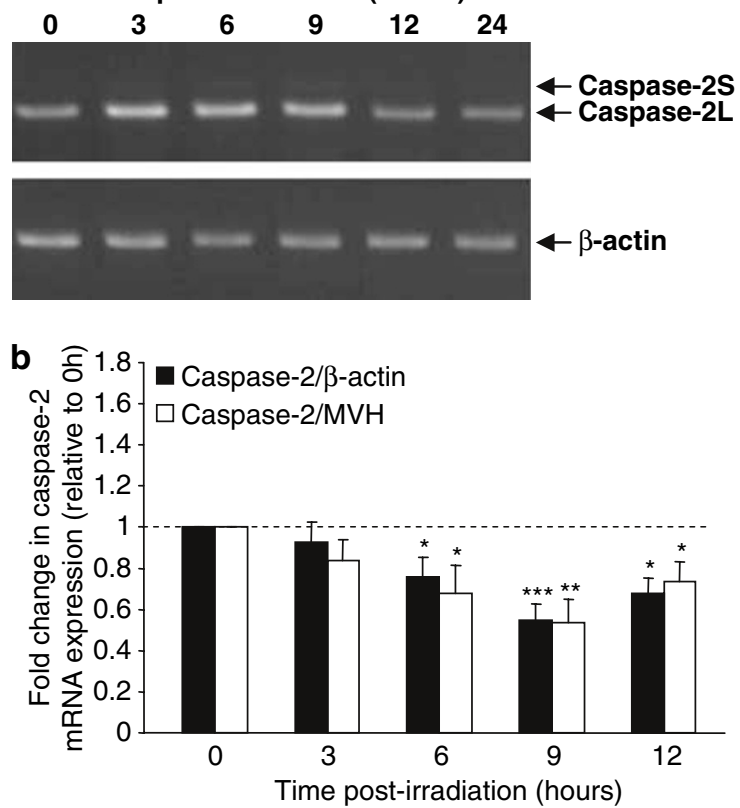

C
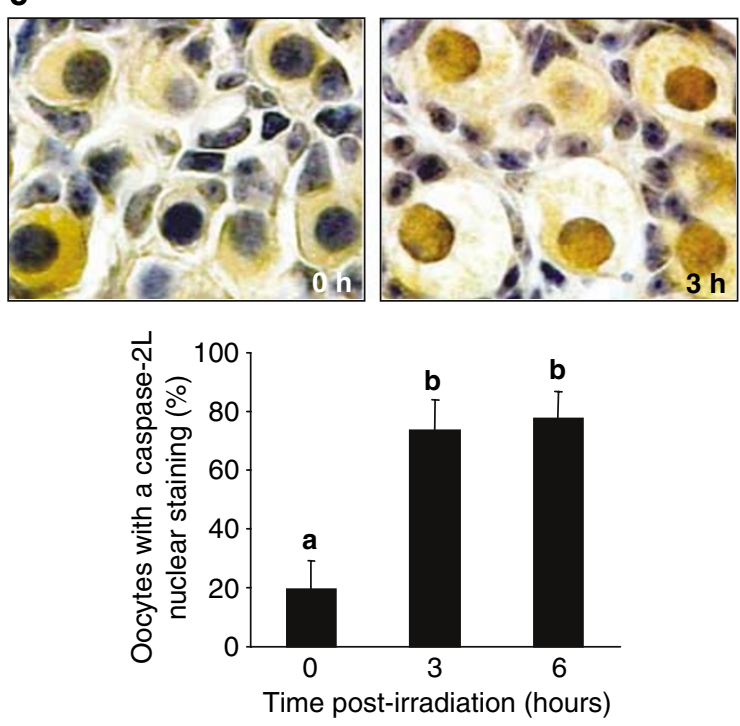

Figure 6 IR (0.5Gy) induces change in caspase-2L mRNA and protein expression. (a) RT-PCR analysis of caspase-2 showed that caspase-2L mRNA was the main mRNA species expressed in control and irradiated ovary. (b) Analysis of caspase-2 mRNA expression by real-time PCR demonstrated a decrease in its level post-IR. $\beta$-Actin and MVH were used as references. Data are the mean \pm S.E.M. of three independent experiments performed in duplicate. (c) Caspase-2L protein was detected specifically in the oocyte and its expression was strongly increased in the nucleus after exposure to $\gamma$-radiation. Data are the mean \pm S.E.M. of three independent experiments. Superscripts are different when values are significantly different $P \leqslant 0.05$

agreement with previous data obtained in the rat ovary. ${ }^{19}$ The radiosensitivity of quiescent oocytes and the relative resistance of growing oocytes remain unexplained. As discussed above, it may be that growing and quiescent oocytes have different basal patterns of expression of pro- and antiapoptotic regulators. Our results tend to support this idea, since caspase-2 expression was very low in growing oocytes but

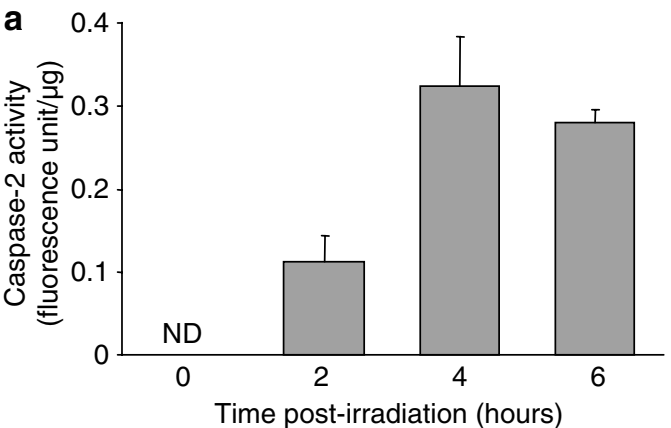

b

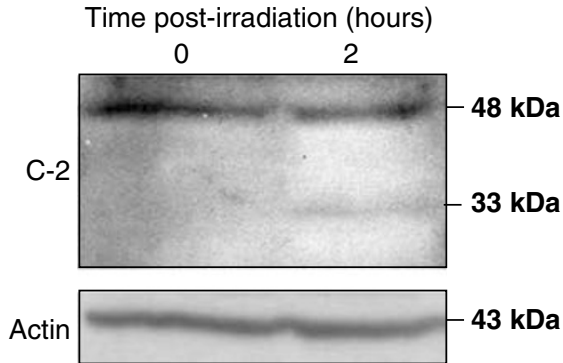

Figure 7 Caspase-2L is activated in the $1 \mathrm{dpp}$ ovary after exposure to irradiation $(0.5 \mathrm{~Gy})$. (a) Caspase-2 activity increased post-IR. Results are the mean \pm S.E.M. of three independent experiments. ND, not detectable. (b) Representative Western blot of caspase-2 showing processing of the zymogen $2 \mathrm{~h}$ post-IR. Membranes were stripped for detection of actin used as reference

strong in quiescent oocytes. One should not, however, exclude an antiapoptotic effect of the follicular environment of growing oocytes, since granulosa cells begin to produce growth factors essential for follicle growth. ${ }^{21}$

We observed a rapid and massive activation of caspase- 9 and -3 after irradiation in the female germ cells, demonstrating that the mitochondrial pathway of apoptosis is activated in oocytes in response to genotoxic stress, as in most DNA damage-induced apoptosis models. ${ }^{20}$ Moreover, by removing female germ cells from the ovarian environment, we show that somatic follicular cells seem to be not required for irradiationinduced apoptosis of the primordial oocytes. So, the intrinsic apoptotic pathway appears to provide an efficient mechanism for the elimination of quiescent oocytes carrying DNA lesions.

One important finding of this report is that caspase- 2 is involved in genotoxic stress-induced oocyte apoptosis. In addition to the predominant caspase-2L mRNA expression previously reported in the mouse ovary, ${ }^{22,23}$ we show here by immunohistochemistry that this proapoptotic factor displays oocyte-specific expression in the postnatal ovary and that exposure to genotoxic stress leads to a decrease in caspase$2 \mathrm{~L}$ mRNA expression in the ovary. As transcriptional activity is repressed in quiescent oocytes from primordial follicle, ${ }^{24}$ this depletion in caspase-2 mRNA could be related to the recruitment of this transcript to the translation process. Indeed, a similar depletion of caspase-2 and other apoptotic mRNAs in response to genotoxic stress has previously been described in the ovulated oocyte known to be in a transcriptional repression state. ${ }^{25}$ Moreover, our results demonstrate early activation of caspase- 2 which precedes the activation of caspase- 9 and -3 , and pretreatment of ovaries with a selective 

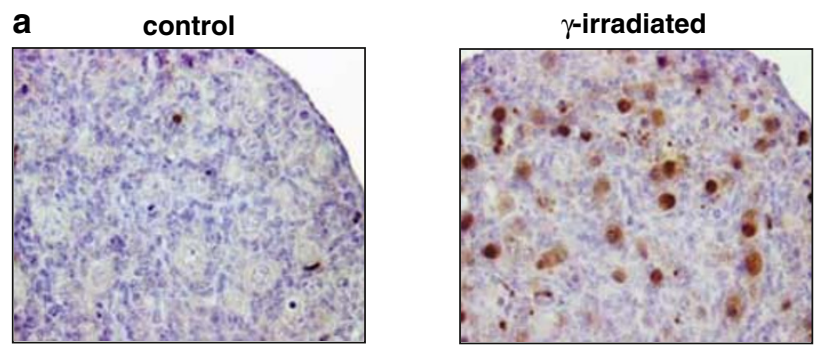

$\gamma$-irradiated+ VDVAD
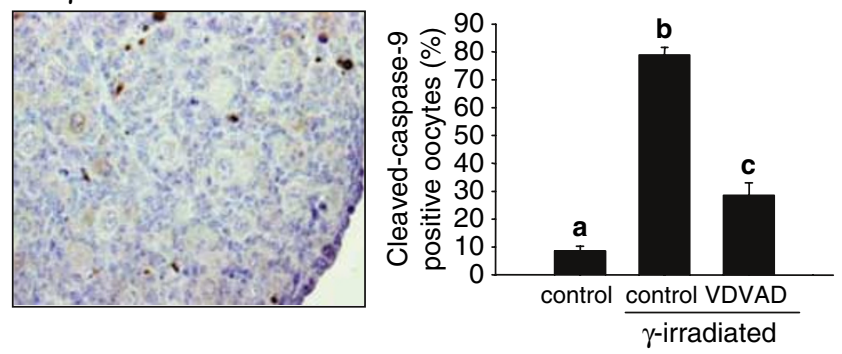

b

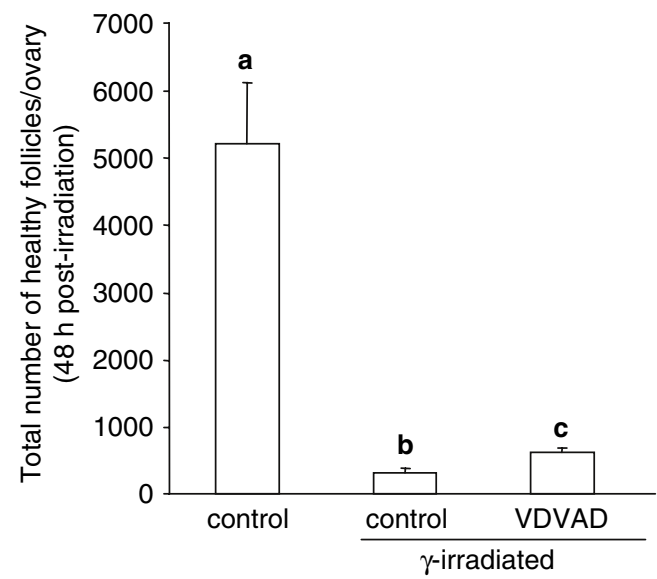

Figure 8 The specific caspase-2 inhibitor z-VDVAD-fmk prevents IR-induced caspase- 9 activation in oocytes (a) but not the IR-induced oocyte loss (b). Ovaries from neonates were pretreated for $1 \mathrm{~h}$ with $z$-VDVAD-fmk $(100 \mu \mathrm{M})$ in an organotypic culture system before exposure to $\gamma$-radiation. They were fixed $9 \mathrm{~h}(\mathrm{a})$ and $48 \mathrm{~h}$ (b) after irradiation respectively for immunohistochemistry analysis of cleaved-caspase- 9 expression and for follicle counting. Pretreatment of ovarian culture with the caspase-2 inhibitor reduced the number of oocytes expressing cleaved caspase-9, and prevented partially the IR-induced oocyte loss. Each column represents the mean \pm S.E.M. of at least three independent experiments. Superscripts are different when values are significantly different $P \leqslant 0.05$

caspase-2 inhibitor (z-VDVAD-fmk) prevents the cleavage of caspase- 9 and -3 in primordial oocytes and ultimately rescues some oocytes. Taken together, our data demonstrate that caspase-2 constitutes an early step in triggering the mitochondrial apoptotic pathway in irradiated quiescent oocytes. Caspase-2 is also involved in the natural apoptotic wave occurring during follicle formation. ${ }^{23}$ Thus, caspase-2 appears to trigger oocyte apoptosis in response to different stimuli such as genotoxic stress and cytokine insufficiency. ${ }^{26}$

Caspase-2 inhibitor prevented the death of some oocytes at $48 \mathrm{~h}$ postirradiation when compared to untreated irradiated ovaries. This indicates that caspase- 2 activated pathway is functional and at least partially required for the IR-induced oocyte death. However, although activation of downstream caspase- 9 and -3 was well prevented by caspase- 2 inhibitor, not all of the oocytes were rescued and most of them died when compared to control ovaries (not irradiated). This suggests that the caspase-2-activated mitochondrial pathway is not the only mechanism triggering oocyte apoptosis after exposure to potent genotoxic stress, or that activation of an alternative pathway occurs to compensate for the loss of caspase-2 functions. In the same line, Takai et a ${ }^{27}$ demonstrated that primordial follicles were not protected from 4-vinylcyclohexene diepoxide (VCD)-induced death in caspase-2- or -3-deficient mice.

Caspase-2 can mediate the recruitment of the mitochondrial apoptotic pathway using different mechanisms. ${ }^{9}$ Active caspase-2 can act directly on mitochondria or cleave cytosolic Bid protein to release cytochrome $c$ and Smac/DIABLO. ${ }^{28}$ Caspase-2 can also trigger cytochrome $c$ release and apoptosis from the nucleus through possible Bid processing. ${ }^{14}$ We observed that $\gamma$-radiation induced an increase in caspase-2 immunostaining in the oocyte cytoplasm as well as in the nucleus, suggesting that caspase- 2 acts both directly and indirectly on mitochondria in triggering oocyte apoptosis in response to genotoxic stress.

Caspase- 2 can be recruited and activated by different mechanisms. Our results tend to demonstrate that caspase-2 activation in irradiated oocytes seems not to be related to a direct interaction of caspase-2 with DNA DSBs revealed by $\gamma \mathrm{H} 2 \mathrm{AX}$ foci. Interestingly, the increase in staining of caspase$2 \mathrm{~L}$ and the depletion in caspase- 2 mRNA post-IR suggest the occurrence of a de novo caspase-2 protein synthesis, which may be functionally important for its activation. It has been documented that overexpression induces dimerization of caspase-2, which constitutes its initial activation. ${ }^{29,30}$ This dimerization promotes the autocleavage between the large and small subunits which is necessary to trigger cell death. ${ }^{29,30}$ However, other mechanisms could be involved in caspase- 2 activation during oocyte apoptosis. Ceramide induces the mitochondrial apoptotic pathway via activation of caspase- $2,{ }^{31}$ and the sphingomyelin pathway is a major signaling pathway that triggers the apoptosis of irradiated oocytes. ${ }^{5}$ Furthermore, a p53-dependent caspase-2 activation involving the formation of the PIDDosome cannot be excluded in irradiated oocytes. ${ }^{32}$ Lastly, the generation of reactive oxygen species (ROS), which occurs after irradiation, has recently been demonstrated to lead to the activation of caspase-2. ${ }^{33}$

In conclusion, we report here essential data concerning the mechanisms involved in the IR-induced depletion of primordial follicle stock occurring after birth, which may serve to maintain genomic integrity. We demonstrate that following genotoxic stress, the disappearance of the follicular reserve involves an early caspase-2-dependent activation of the apoptotic mitochondrial pathway in quiescent oocytes. Moreover, caspase-2 expression is well correlated with oocyte radiosensitivity throughout ovarian development, emphasizing that this caspase may play an important role in triggering the genotoxic stress-induced apoptosis of female germ cells.

\section{Materials and Methods}

Animals, whole-body $\gamma$-irradiation and tissue processing. Female NMRI mice were housed individually under controlled photoperiod conditions (lights 
a
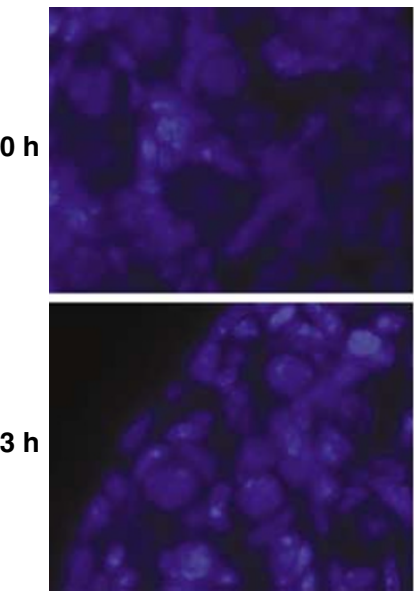

b

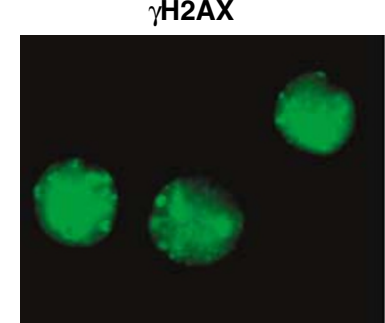

$\gamma \mathrm{H} 2 \mathrm{AX}$
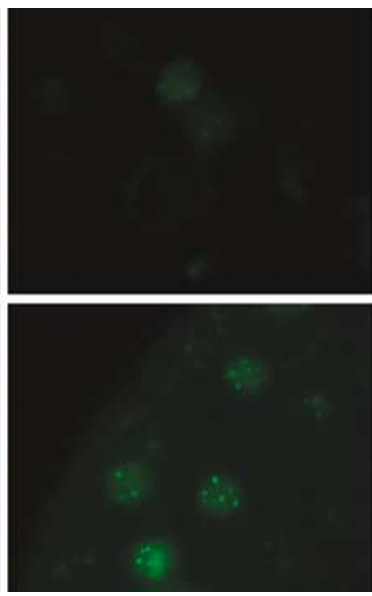

Caspase-2L

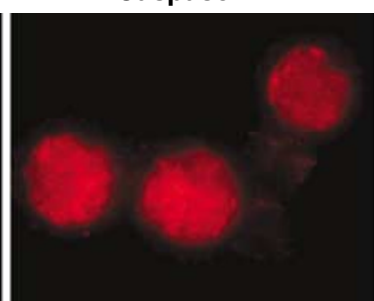

MERGE
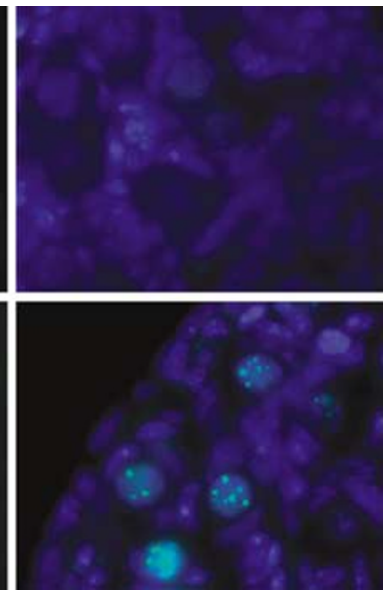

MERGE

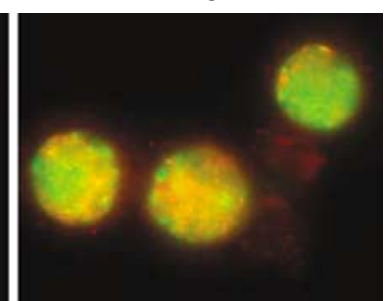

Figure $9 \mathrm{IR}(0.5 \mathrm{~Gy})$ induces the appearance of $\gamma \mathrm{H} 2 \mathrm{AX}$ foci in the oocyte nucleus. (a) Immunofluorescence for $\gamma \mathrm{H} 2 \mathrm{AX}$ on ovarian sections revealed the appearance of foci specifically in the oocyte nucleus $3 \mathrm{~h}$ post-IR. (b) Costaining of oocytes for $\gamma \mathrm{H} 2 \mathrm{AX}$ and caspase-2L did not show colocalization of caspase-2L with $\gamma \mathrm{H} 2 \mathrm{AX}$ foci. The results presented are representative of at least three independent experiments

on 0800-2000 h) and were supplied with commercial feed and tap water ad libitum. The day after an overnight mating was counted as day 0.5 postconception $(0.5 \mathrm{dpc})$. Natural birth occurred on $19.5 \mathrm{dpc}$, which was counted as day 0 postpartum ( $0 \mathrm{dpp}$ ). All animal studies were conducted in accordance with the NIH Guide for Care and Use of Laboratory Animals.

To evaluate the effect of IR during ovarian development, animals at $12.5,14.5$, $18.5 \mathrm{dpc}$ and $1 \mathrm{dpp}$ were whole-body exposed to $\gamma$-irradiation using a ${ }^{137} \mathrm{Cs}$ isotopic source with a total dose of $1.5 \mathrm{~Gy}$ at a dose rate of $0.62 \mathrm{~Gy} / \mathrm{min}$. Fetuses were exposed to IR in utero and left with their mother after birth. Ovaries were collected at $8 \mathrm{dpp}$, fixed immediately in Bouin's fixative or in $4 \%$ paraformaldehyde for at least $1 \mathrm{~h}$, dehydrated in alcohol, paraffin-embedded and then cut into $5 \mu \mathrm{m}$ sections.

The IR-induced follicular death was studied in neonate ovaries. Animals $1 \mathrm{dpp}$ old were whole-body $\gamma$-irradiated with a total dose of $0.5 \mathrm{~Gy}$ at a dose rate of $0.62 \mathrm{~Gy} / \mathrm{min}$ and ovaries were collected at $0,1,2,3,4,5,6,9,12,24$ and $48 \mathrm{~h}$ postirradiation. For immunohistochemistry, they were processed as described above. For Western blotting, ovaries were frozen in liquid nitrogen, then stored at $-80^{\circ} \mathrm{C}$ until protein extraction, and for RT-PCR analysis they were frozen in RLT buffer from the RNeasy Plus Mini Kit (Qiagen, S.A., Courtaboeuf, France) until RNA extraction as suggested by the manufacturer.

Organ culture. Ovaries were collected at $0 \mathrm{dpp}$, cut into two pieces and placed on a Millicell filter (Millipore, Billerica, MA; pore size: $0.45 \mu \mathrm{m}$ ). The filter was floated on DMEM:HAM-F12 (50\% v/v) (Invitrogen, Cergy Pontoise, France) supplemented with $15 \mathrm{mM}$ HEPES (Invitrogen), $40 \mu \mathrm{g} / \mathrm{ml}$ gentamycin (Sigma-Aldrich, Lyon, France), $1 \%$ fetal calf serum (FCS) (Invitrogen) on 24-well culture plate (Nunc), and incubated at $37^{\circ} \mathrm{C}$ in an atmosphere of $5 \% \mathrm{CO}_{2}$. After $24 \mathrm{~h}$, organs were cultured in the presence or absence of the caspase-2 inhibitor z-VDVAD-fmk $(100 \mu \mathrm{M})$ (Santa Cruz Biotechnologies, CA, USA) for $1 \mathrm{~h}$, then exposed to 0.5 Gy of $\gamma$ irradiation. Culture medium was replaced with fresh medium with or without the caspase inhibitors. After $9 \mathrm{~h}$ or $48 \mathrm{~h}$, ovaries were fixed in Bouin's fixative for at least $1 \mathrm{~h}$, dehydrated in alcohol and paraffin-embedded for immunohistochemistry analysis.
Culture of dispersed ovarian cells. Ovaries were collected at $0 \mathrm{dpp}$, and then digested using $0.5 \mathrm{mg} / \mathrm{ml}$ collagenase, $20 \mu \mathrm{g} / \mathrm{ml}$ DNase I and $1 \times$ trypsin/ EDTA (Sigma). This procedure results in detachment of the layer of granulosa cells from the oocytes, thereby enabling isolation of ovarian cells. The suspension of ovarian cells was cultured on four-well Labtek (Nunc) in DMEM:HAM-F12 supplemented with $15 \mathrm{mM}$ HEPES, $40 \mu \mathrm{g} / \mathrm{ml}$ gentamycin, $1 \%$ FCS for $24 \mathrm{~h}$ to allow cell attachment and then $\gamma$-irradiated with a total dose of $0.5 \mathrm{~Gy}$. After replacement of culture medium, cells were fixed at $3 \mathrm{~h}$ postirradiation with $-20^{\circ} \mathrm{C}$ methanol for $5 \mathrm{~min}$, and then analyzed by immunofluorescence.

Isolation of neonatal oocytes. Oocytes from dispersed $1 \mathrm{dpp}$ ovarian cells were sorted according to their round shape and larger size using a micromanipulator system (CellTram Oil, Eppendorf, Le Pecq, France) placed on an inverted microscope (Axiovert 200, Zeiss). The purity of the germ cell fraction was assayed by RT-PCR using two specific oocyte markers: MSY2 (primer forward: $5^{\prime}$ CAGCCTATAGCCGCAGAGAC-3' and primer reverse: $5^{\prime}$-GGTGATGCCT CGGAACAATA-3') and c-kit (primer forward: $5^{\prime}$-AATGGCCTCACGAGTTCTAT-3' and primer reverse: $5^{\prime}$-ATGGAGTTCACGGATGTAGA-3') and FOXL-2 (primer forward: $5^{\prime}$-AAGCCCCCGTACTCGTACGTGGCGCTCATC- $3^{\prime}$ and primer reverse: $5^{\prime}$-GTAGTTGCCCTTCTCGAACATGTC-3') as somatic cell marker.

Hoechst staining of isolated oocytes. The number of apoptotic sorted oocytes was measured by assessing the percentage of oocytes displaying condensed nuclei. Briefly, after isolation, oocytes were placed in DMEM:HAM-F12 supplemented with $15 \mathrm{mM}$ HEPES, $40 \mu \mathrm{g} / \mathrm{ml}$ gentamycin, $1 \%$ FCS and then $\gamma$-irradiated with a total dose of $0.5 \mathrm{~Gy}$. After $8 \mathrm{~h}$, sorted oocytes were fixed in $4 \%$ paraformaldehyde for $20 \mathrm{~min}$ at $4{ }^{\circ} \mathrm{C}$, washed with PBS, transferred to SuperfrostPlus slides and air-dried. Then, oocytes were permeabilized with $0.1 \%$ Triton X-100, stained for $\mathrm{MVH}$ by immunofluorescence and the nuclear chromatin was counterstained with Hoechst $33342(5 \mu \mathrm{g} / \mathrm{ml})$ for $20 \mathrm{~min}$.

Propidium iodide incorporation of isolated oocytes. Sorted oocytes were placed in DMEM:HAM-F12 supplemented with $15 \mathrm{mM} \mathrm{HEPES,} 40 \mu \mathrm{g} / \mathrm{ml}$ 

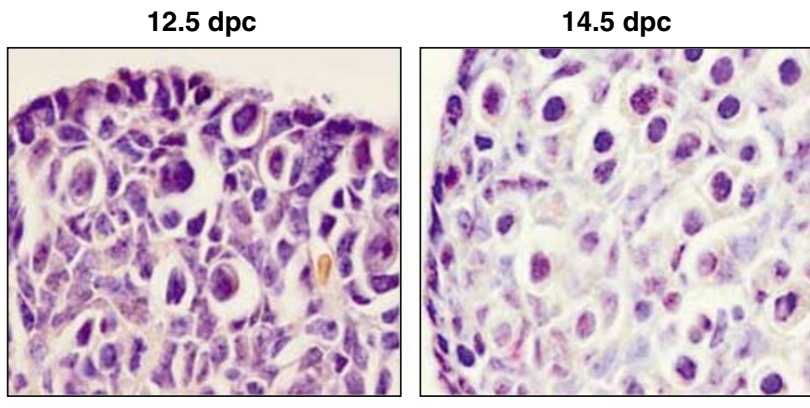

$17.5 \mathrm{dpc}$

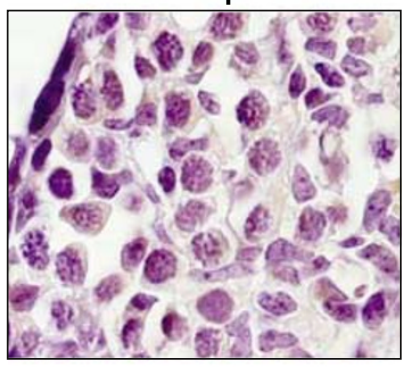

$1 \mathrm{dpp}$
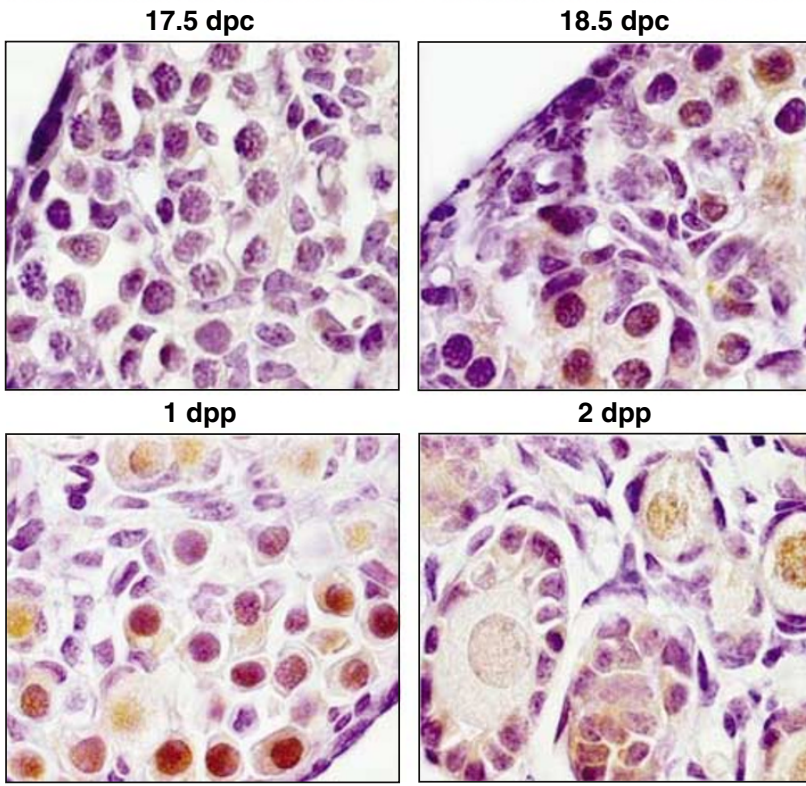

2 dpp

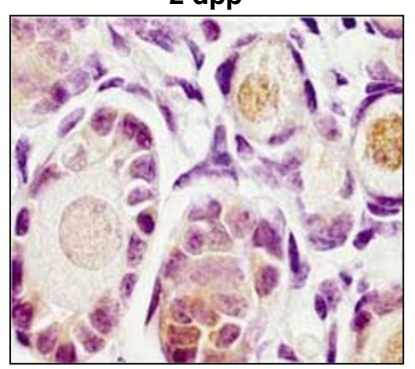

Figure 10 Caspase-2L expression correlates with oocyte radiosensitivity throughout ovarian development. Caspase-2L expression during ovarian development was analyzed by immunohistochemistry. Staining was barely visible during the radioresistance stages and strong during the radiosensitivity stages

gentamycin, $1 \%$ FCS and then $\gamma$-irradiated with a total dose of $0.5 \mathrm{~Gy}$. After $16 \mathrm{~h}$ of culture, oocytes were incubated for 20 min with propidium iodide (PI) $(1 \mu \mathrm{g} / \mathrm{ml})$ and Hoechst $33342(1 \mu \mathrm{g} / \mathrm{ml})$ to assess the percentage of dead cells after irradiation.

Quantification of follicle number. Five $\mu \mathrm{m}$ sections were mounted on glass slides and stained with hematoxylin-eosin. The follicles were counted in every tenth section using the oocyte nucleus as a marker, and the stage of follicular development was determined as previously described. ${ }^{18}$ Briefly, follicles were classified according to the shape and number of layers of somatic cells that surrounded the oocyte: primordial with flattened cells, primary with one layer of cuboidal cells and secondary with two partial or complete layers of cells. Atretic follicles were identified due to the presence of a degenerating oocyte or of several pyknotic cells.

Electronic microscopy. Ovaries were fixed in $2.5 \%$ glutaraldehyde in cacodylate buffer before being postfixed in $1 \% \mathrm{OsO}_{4}$. They were then dehydrated in graded alcohols followed by propylene oxide. Embedding was carried out in Durkupan (Fluka). Semi-thin sections were stained with toluidine blue. Ultrathin sections were counterstained with uranyl acetate and lead citrate. Observations were made using a Jeol-1010 electron microscope.

Immunohistochemistry. Tissue sections $(5 \mu \mathrm{m})$ were mounted on glass slides and boiled for $10 \mathrm{~min}$ in $10 \mathrm{mM}$ Tris $\mathrm{pH} 10.6$ for antigen unmasking. Endogenous peroxidase activity was blocked with $3 \%$ hydrogen peroxide for $10 \mathrm{~min}$. Slides were incubated with the primary antibody overnight at $4{ }^{\circ} \mathrm{C}$. The primary antibodies used were rabbit anticleaved caspase-3 Asp 175 (diluted 1:100) (Cell
Signaling Technology, Beverly, MA, USA), rabbit anticleaved caspase-9 Asp 353 (diluted 1:100) (Cell Signaling Technology), and rabbit anticaspase-2L sc-626 (diluted 1:250) (Santa Cruz Biotechnologies). After washing in PBS, slides were incubated for $30 \mathrm{~min}$ at room temperature with a biotinylated goat anti-rabbit antibody diluted 1:200 (Vector Laboratories, Peterborough, England), and then for $30 \mathrm{~min}$ with the avidin-biotin-peroxidase complex (Vector Laboratories). Peroxidase activity was visualized using $3,3^{\prime}$-diaminobenzidine (DAB) as substrate. Finally, slides were counterstained with hematoxylin.

Caspase-2 activity assay. Caspase-2 activity in ovarian lysates following exposure to IR was assayed using the Fluorometric Caspase-2 Assay Kit (Calbiochem, La Jolla, CA, USA) according to the manufacturer's instructions. Briefly, ovarian lysates were incubated for $2 \mathrm{~h}$ at $37^{\circ} \mathrm{C}$ with VDVAD-AFC substrate $(50 \mu \mathrm{M})$ in the presence or absence of z-VDVAD-fmk $(100 \mathrm{nM})$ in the reaction buffer. Cleavage of the fluorogenic peptide substrate was monitored by AFC release using $400 \mathrm{~nm}$ excitation and $505 \mathrm{~nm}$ emission wavelengths. Specific caspase-2 activity was considered to be the VAVADase. The total protein concentration was determined for each sample and data were normalized to the quantity of total protein used for the assay.

Terminal deoxynucleotidyltransferase-mediated deoxyuridine 5 '-triphosphate-fluorescein nick end labeling. Apoptotic cells were detected on $4 \%$ paraformaldehyde-fixed ovarian sections $(5 \mu \mathrm{m})$ using the in situ Cell Death Detection Kit, POD (Roche, Diagnostics, Switzerland) according to the manufacturer's instructions.

Immunofluorescence. Fixed ovarian cells or fixed ovarian sections were incubated for $1 \mathrm{~h}$ with the primary antibodies at room temperature. The primary antibodies used were mouse anti- $\gamma \mathrm{H} 2 \mathrm{AX}$ (diluted 1:200) (Upstate - Cell Signaling Solutions), rabbit anti-MVH (diluted 1:500) (Abcam) and rabbit anticaspase-2L sc-626. After washing in PBS, cells were incubated for 45 min with a donkey antimouse IgG-FITC (diluted 1:200) (Jackson ImmunoResearch Laboratories) or with a donkey anti-rabbit-Cy3 (diluted 1:1000) (Jackson ImmunoResearch Laboratories). Slides were mounted with Vectashield with or without Dapi (Vector Laboratories) and analyzed by conventional immunofluorescence microscopy using a Provis AX70 Olympus microscope.

RNA extraction and RT-PCR. Total RNA from $1 \mathrm{dpp}$ ovaries was extracted using the RNeasy Plus Mini Kit (Qiagen), and $500 \mathrm{ng}$ of total RNA were reversetranscribed using the Omniscript Reverse Transcription kit (Qiagen) according to the kit instructions.

PCR was performed to study the expression of caspase-2 isoforms after $\gamma$-irradiation. Primers for caspase-2L and -2S amplification were: forward $5^{\prime}$-TTTTTCGACTTTTTGACAATGC-3' and reverse $5^{\prime}$-GCATGTCACAAGCTCTTT CAG-3'; and for $\beta$-actin amplification, used as reference: forward $5^{\prime}$-AAGAGAGG TATCCTGACCCTG- $3^{\prime}$ and reverse $5^{\prime}$-GGCCATCTCCTGCTCGAAGT-3'. PCR was performed using $1 \mu \mathrm{l} \mathrm{CDNA}, 3 \mathrm{pmol}$ of each primer (Invitrogen), $0.2 \mathrm{mM}$ of each dNTP (Invitrogen), $2 \mathrm{mM} \mathrm{MgCl} 2$ (Invitrogen), $1 \cup$ Taq DNA polymerase (Invitrogen) in the reaction buffer $(20 \mathrm{mM}$ Tris- $\mathrm{HCl}(\mathrm{pH} 8.4), 50 \mathrm{mM} \mathrm{KCl})$ in a final volume of $25 \mu \mathrm{l}$. PCR conditions were: $\left(3 \mathrm{~min} / 94^{\circ} \mathrm{C}\right), 30$ cycles $\left(45 \mathrm{~s} / 94^{\circ} \mathrm{C}, 1 \mathrm{~min} / 56^{\circ} \mathrm{C}, 1 \mathrm{~min} /\right.$ $\left.72^{\circ} \mathrm{C}\right)$ for caspase-2 and $\left(2 \mathrm{~min} / 94^{\circ} \mathrm{C}\right), 26$ cycles $\left(45 \mathrm{~s} / 94^{\circ} \mathrm{C}, 50 \mathrm{~s} / 50^{\circ} \mathrm{C}, 1 \mathrm{~min} /\right.$ $72^{\circ} \mathrm{C}$ ) for $\beta$-actin.

Amplification products were separated on 2 or $3 \%$ agarose gel stained with ethidium bromide (Sigma) $(1 \mu \mathrm{g} / \mathrm{ml})$.

Real-time quantitative PCR. Real-time PCRs were performed using the $A B \mid$ Prism 7000 Sequence Detection system (Applied Biosystems, Courtaboeuf, France) according to the manufacturer's instructions. Primers for caspase-2 quantification were: forward $5^{\prime}$-CCACAGATGCTACGGAACA-3' and reverse $5^{\prime}$-GCTGGTAGTGTGCCTGGTAA-3'; for $\beta$-actin, used as reference: forward $5^{\prime}$-TGACCCAGATCATGTTTGAGA- $3^{\prime}$ and reverse $5^{\prime}$-TACGACCAGAGGCATAC AGG-3'; and for MVH, used also as reference: forward $5^{\prime}$ GAAGAAATCCAGA GGTTGGC- $3^{\prime}$ and reverse $5^{\prime}$ GAAGGATCGTCTGCTGAACA- $3^{\prime}$. Caspase-2, $\beta$ actin and MVH mRNAs were quantified using the SYBR Green Universal PCR Master Mix $2 \times$ (Applied Biosystem) in a total volume of $30 \mu$ l. Samples were heated for $10 \mathrm{~min}$ at $95^{\circ} \mathrm{C}$, followed by 40 cycles of $15 \mathrm{~s}$ at $95^{\circ} \mathrm{C}$ then $1 \mathrm{~min}$ at $60^{\circ} \mathrm{C}$ The statistical significance of differences in mRNA expression was analyzed by the Relative Expression Software Tool (REST) ${ }^{34}$ PCR efficiencies for caspase-2, $\beta$-actin and MVH were $2.07,1.98$ and 1.89 , respectively. 
Protein extraction and Western blotting. Ovaries (1 $\mathrm{dpp}$ ) were resuspended in homogenization buffer $(20 \mathrm{mM}$ Tris base pH 8.0 (Sigma) containing $150 \mathrm{mM} \mathrm{NaCl}$ (Sigma), $0.5 \mathrm{mM}$ EDTA (Sigma), 1\% Triton X 100 (Sigma), $0.1 \%$ sodium dodecyl sulfate (SDS) (Sigma), $10 \mathrm{mM}$ sodium fluoride (NaF) (Sigma), $1 \mathrm{mM}$ sodium orthovanadate ( $\mathrm{NaO}$ ) (Sigma), $10 \mathrm{mM} \beta$-glycerophosphate (Sigma) and protease inhibitor cocktail ( 1 tablet/10 $\mathrm{ml}$ extraction solution, (Roche)). Samples were placed on ice for $30 \mathrm{~min}$, homogenized every $5 \mathrm{~min}$ and then centrifuged at $4^{\circ} \mathrm{C}$ for $15 \mathrm{~min}$ at $11000 \mathrm{~g}$ to remove cellular debris, and the protein concentration in the supernatant was measured by the Bradford method. Finally, samples were frozen at $-20^{\circ} \mathrm{C}$ until Western blotting.

Total proteins $(50 \mu \mathrm{g})$ were separated on a $12 \%$ polyacrylamide denaturing gel using Tris/glycine/SDS running buffer ( $25 \mathrm{mM}$ Tris base (Sigma), $200 \mathrm{mM}$ glycine (pH 8.3) (Sigma), $0.1 \%$ SDS (Sigma)) and were blotted onto PVDF membranes (Amersham Biosciences, Saclay, France). Membranes were blocked for $1 \mathrm{~h}$ at room temperature in Tris-buffered saline (TBS) pH 7.4 containing $0.05 \%$ Tween 20 (Sigma) and $5 \%$ non-fat dried milk, then incubated overnight at $4{ }^{\circ} \mathrm{C}$ with a mouse anticaspase-2 (Cell Signaling Technologies) diluted 1:100 in the blocking solution. Membranes were incubated for $1 \mathrm{~h}$ at room temperature with a goat anti-mouse IgG:HRP-linked antibody (Amersham) diluted 1:5,000 in the blocking solution. Antibody-protein complexes were visualized using the enhanced chemiluminescence (ECL) visualization system (Amersham).

Membranes were stripped to detect actin used as reference. Briefly, they were incubated for $15 \mathrm{~min}$ in a stripping buffer $(62.5 \mathrm{mM}$ Tris- $\mathrm{HCl} \mathrm{pH} 6.8$ (Sigma), $2 \%$ SDS (Sigma), $100 \mathrm{mM} \beta$-mercaptoethanol (Sigma)). Actin expression was detected as described above using a mouse monoclonal antiactin (CP01) antibody (Calbiochem)

Data analysis. Each data point represents the mean \pm S.E.M. of at least three independent experiments. Images show a representative experiment that was repeated at least three times. Data were analyzed using Graphpad Instat 3.0, by one-way ANOVA followed by the Tukey-Kramer multiple comparisons test.

Acknowledgements. This work was supported by Electricité De France (EDF). We thank V Neuville, S Leblay and C Chauveau for taking care of the animals, A Gouret for her secretarial help and D Marsh for his useful critical review of this manuscript.

1. Skinner MK. Regulation of primordial follicle assembly and development. Hum Reprod Update 2005; 11 (5): 461-471

2. Johnson J, Canning J, Kaneko T, Pru JK, Tilly JL. Germline stem cells and follicular renewal in the postnatal mammalian ovary. Nature 2004; 428: 145-150.

3. Johnson JL, Bagley J, Skaznik-Wikiel M, Lee HJ, Adams GB, Niikura Y et al. Oocyte regeneration in adult mammalian ovaries by putative germ cells in bone marrow and peripheral blood. Cell 2005; 122: 303-315.

4. Meirow D, Nugent D. The effects of radiotherapy and chemotherapy on female reproduction. Hum Reprod Update 2001; 7 (6): 535-543.

5. Morita Y, Perez Gl, Paris F, Miranda SR, Ehleiter D, Haimovitz-Friedman A et al. Oocyte apoptosis is suppressed by disruption of the acid sphingomyelinase gene or by sphingosine-1-phosphate therapy. Nat Med 2000; 6 (10): 1109-1114.

6. Prise KM, Schettino G, Folkard M, Held KD. New insights on cell death from radiation exposure. Lancet Oncol 2005; 6: 520-528.

7. Haimovitz-Friedman A, Kan CC, Ehleiter D, Persaud RS, McLoughlin M, Fuks Z et al. Ionizing radiation acts on cellular membranes to generate ceramide and initiate apoptosis. J Exp Med 1994; 180: 525-535.

8. Wang X. The expanding role of mitochondria in apoptosis. Genes Dev 2001; 15 2922-2933.

9. Zhivotovsky B, Orennius S. Caspase-2 function in response to DNA damage. Biochem Biophys Res Commun 2005; 331: 859-867.
10. Wang L, Miura M, Bergeron L, Zhu H, Yuan J. Ich-1, an Ice/ced-3-related gene, encodes both positive and negative regulators of programmed cell death. Cell 1994; 78: 739-750.

11. Kumar S, Kinoshita M, Dorstyn L, Noda M. Origin, expression and possible functions of the two alternatively spliced forms of the mouse Nedd2 mRNA. Cell Death Differ 1997; 4: 378-387.

12. Lassus $P$, Opitz-Araya $X$, Lazebnik $Y$. Requirement for caspase-2 in stress-induced apoptosis before mitochondrial permeabilization. Science 2002; 297: 1352-1354.

13. Harvey NL, Butt AJ, Kumar S. Functional activation of Nedd2/ICH-1 (caspase-2) is an early process in apoptosis. J Biol Chem 1997; 272 (20): 13134-13139.

14. Paroni G, Henderson C, Schneider C, Brancolini C. Caspase-2 can trigger cytochrome $C$ release and apoptosis from the nucleus. J Biol Chem 2002; 277 (17): 15147-15161.

15. McClellan KA, Gosden R, Taketo T. Continuous loss of oocytes throughout meiotic prophase in the normal mouse ovary. Dev Biol 2003; 258: 334-348.

16. Takanami T, Mori A, Takahashi H, Higashitani A. Hyper-resistance of meiotic cells to radiation due to a strong expression of a single recA-like gene in Caenorhabditis elegans. Nucleic Acids Res 2000; 28 (21): 4232-4236.

17. Rinaldo C, Bazzicalupo P, Ederle S, Hilliard M, La Volpe A. Roles for Caenorhabditis elegans rad-51 in meiosis and in resistance to ionizing radiation during development. Genetics 2002; 160: 471-479.

18. Mazaud S, Guigon CJ, Lozach A, Coudouel N, Forest MG, Coffigny H et al. Establishment of the reproductive function and transient fertility of female rats lacking primordial follicle stock after fetal-irradiation. Endocrinology 2002; 143: 4775-4787.

19. Guigon CJ, Mazaud S, Forest MG, Brailly-Tabard S, Coudouel N, Magre S. Unaltered development of the initial follicular waves and normal pubertal onset in female rats after neonatal deletion of the follicular reserve. Endocrinology 2003; 144: 3651-3662.

20. Norbury CJ, Zhivotovsky B. DNA damage-induced apoptosis. Oncogene 2004; 23: 2797-2808.

21. Van Den Hurk $R$, Zhao J. Formation of mammalian oocytes and their growth, differentiation and maturation within ovarian follicles. Theriogenology 2005; 63 (6): 1717-1751.

22. Flaws JA, Kugu K, Trbovich AM, DeSanti A, Tilly KI, Hirshfield AN et al. Interleukin-a betaconverting enzyme-related proteases (IRPs) and mammalian cell death: dissociation of IRP-induced oligonucleosomal endonuclease activity from morphological apoptosis in granulosa cells of the ovarian follicle. Endocrinology 1995; 136: 5042-5053.

23. Bergeron L, Perez GI, Macdonald G, Shi L, Sun Y, Jurisicova A et al. Defects in regulation of apoptosis in capase-2-deficient mice. Genes Dev 1998; 12: 1304-1314.

24. Serafica MD, Goto T, Trounson AO. Transcripts from a human primordial follicle cDNA library. Hum Reprod 2005; 20 (8): 2074-2091.

25. Jurisicova A, Lee HJ, D'Estaing SG, Tilly J, Perez GI. Molecular requirements for doxorubicin-mediated death in murine oocytes. Cell Death Differ 2006; 13: 1466-1474.

26. Morita Y, Maravei DV, Bergeron L, Wang S, Perez GI, Tsutsumi O et al. Caspase-2 deficiency prevents programmed germ cells death resulting from cytokine insufficiency but not meiotic defects caused by loss of ataxia telangiectasia-mutated (Atm) gene function. Cell Death Differ 2001; 8: 614-620.

27. Takai Y, Canning J, Perez GI, Pru JK, Schlezinger JJ, Sherr DH et al. Bax, caspase-2, and caspase-3 are required for ovarian follicle loss caused by 4-vinylcyclohexene diepoxide exposure of female mice in vivo. Endocrinology 2003; 144: 69-74.

28. Guo Y, Srinivasula SM, Druilhe A, Fernandes-Alnemri T, Alnemri ES. Caspase-2 induces apoptosis by releasing proapoptotic proteins from mitochondria. J Biol Chem 2002; 277 (16): 13430-13437

29. Butt AJ, Harvey NL, Parasivam G, Kumar S. Dimerization and autoprocessing of the Nedd2 (caspase-2) precursor requires both the prodomain and the carboxyl-terminal regions. J Biol Chem 1997; 273 (12): 6763-6768.

30. Baliga BC, Read SH, Kumar S. The biochemical mechanism of caspase-2 activation. Cell Death Differ 2004; 11: 1234-1241

31. Lin CF, Chen CL, Chang WT, Jan MS, Hsu LJ, Wu RH et al. Sequential caspase-2 and caspase-8 activation upstream of mitochondria during ceramide- and etoposide-induced apoptosis. J Biol Chem 2004; 279 (39): 40755-40761.

32. Tinel A, Tschopp J. The PIDDosome, a protein complex implicated in activation of caspase2 in response to genotoxic stress. Science 2004; 304: 843-846.

33. Prasad V, Chandele A, Jagtap JC, Kumar PS, Shastry P. ROS-triggered caspase 2 activation and feedback amplification loop in beta-carotene-induced apoptosis. Free Radic Biol Med 2006; 41 (3): 431-442.

34. Pfaffl MW, Horgan GW, Dempfle L. Relative expression software tool (RESTC) for groupe-wise comparison and statistical analysis of relative expression results in real-time PCR. Nucleic Acids Res 2002; 30: e36. 